\title{
Diagnostic Accuracy of Hand Surgeons and Pain Specialists in Diagnosing CRPS Based on the Budapest Criteria
}

\author{
Pattariya Jänsch \\ Unfallkrankenhaus Berlin \\ Ariane Asmus \\ Unfallkrankenhaus Berlin
}

\section{Sofia Pappa-Eisenschenk}

Unfallbehandlungsstelle Berlin

\section{Andreas Eisenschenk}

Unfallkrankenhaus Berlin

\section{Michael Miillrose}

BG Klinik Murnau

\section{Joscha Diehl}

\section{Universität Greifswald}

Simon Kim ( $\nabla$ simon.kim@uni-greifswald.de)

Universitatsmedizin Greifswald Klinik für Unfallchirurgie https://orcid.org/0000-0002-7455-7421

\section{Research article}

Keywords: CRPS, Budapest criteria, diagnostic accuracy

Posted Date: June 23rd, 2020

DOI: https://doi.org/10.21203/rs.3.rs-36214/v1

License: (9) This work is licensed under a Creative Commons Attribution 4.0 International License. Read Full License 


\section{Abstract}

\section{Background}

The clinical presentation of complex regional pain syndrome is heterogenous. The Budapest criteria give a list of symptoms and signs for the diagnosis. But the physician will often set the diagnosis clinically from the collection of symptoms and his or her experience. This study examines the accuracy of hand surgeons and pain specialists for diagnosing CRPS using the Budapest criteria as reference.

\section{Methods}

We included 124 patients of which 120 were diagnosed CRPS either by a clinician or by Budapest criteria. We analysed epidemiologic data, the number of patients with CRPS and mode of diagnosis and determined the CRPS severity score. Sensitivity, specificity, accuracy, and predictive values were calculated for hand surgeon and pain specialist. The number of CRPS-NOS was determined. We calculated the agreement between hand surgeon and pain specialist for the diagnosis CRPS.

Results

The Budapest criteria were met in 108 cases with a mean CSS of 10.41 points. Sensitivity of hand surgeons for the diagnosis CRPS was $92 \%$, specificity $31 \%$ and accuracy $90 \%$. The pain specialists had a sensitivity of $74 \%$, specificity of $71 \%$ and accuracy of $74 \%$. Prevalence of CRPS-NOS was $9 \%$. In cases where hand surgeon and pain specialist agreed on CRPS, the Budapest criteria were met in $96 \%$, in all other combinations they were met in around $70 \%$. The agreement of hand surgeon and pain specialist was fair.

\section{Conclusion}

The Budapest criteria can support the diagnosis CRPS in clinically ambiguous cases as they were most often met in cases with agreement of both clinicians. Care must be taken not to miss patients with CRPSNOS.

Trial registration

The study was registered in the German Clinical Trials Register: DRKS00020348

Universal Trial Number (UTN): U1111-1245-4109

\section{Background}

The complex regional pain syndrome (CRPS) is a chronic illness that may affect an extremity following a traumatic event in most cases $(1-4)$. Due to the heterogenous clinical presentation, the diagnosis is based on a combination of symptoms and diagnostic results (5). The most recent Budapest criteria help recognise the disease which relies on patient-reported symptoms and clinical findings (6). Further 
classification may depend on the existence of a nerve lesion (CRPS type I and II) (7) or by the CRPS severity score (CSS) $(8,9)$. Depending on the selected criteria, the sensitivity ranges from $78-99 \%$ with a specificity of $68-79 \%(6,10)$. We analysed the accuracy of hand surgeons and anaesthesiologists who work as pain specialists and diagnose the disease based on clinical symptoms and their experience using the Budapest criteria as reference.

\section{Methods}

We searched the database of our stationary rehabilitation department for patients between 01.01.2010 and 31.12.2013 who were referred with the diagnosis CRPS or received the diagnosis on admission. We found 150 eligible patients and contacted them for consent which was obtained from 124 patients. Two patients had passed away, one patient declined participation and 23 did not reply. Nineteen patients were admitted at least twice during the examined period because of persistent symptoms or new occurrence of CRPS on the other side. We included only the first presentation of each patient during the included time period in this study.

Each patient was seen by one of six hand surgeons on admission who would clinically determine the presence of CRPS and CRPS type and check the items for Budapest diagnostic criteria and 16-point CSS $(9,11)$. For this retrospective study we analysed the criteria for clinical purposes, requiring two of four sign categories and three of four symptom categories and gave the diagnosis 'CRPS-not otherwise specified' (CRPS-NOS) as recommended by Harden et al. (11).

In most cases, the patient would be presented to one of four anaesthetists with specialisation in pain therapy within one week after admission who would clinically decide on the presence of CRPS. All physicians had at least 10 years of experience with the treatment of CRPS.

We examined sex, age at clinical diagnosis or suspicion of CRPS, affected side, and handedness.

Using the Budapest Criteria as reference, we calculated sensitivity, specificity, positive and negative likelihood ratio, positive and negative predictive value and accuracy of hand surgeons and pain specialists for clinically diagnosing CRPS. Values are given with standard deviation of the mean (SD) and $95 \%$ confidence interval $(\mathrm{Cl})$. We used the prevalence in our sample for predictive values and considered patients who either met the Budapest criteria or received the clinical diagnosis from either or both clinicians. Cohen's kappa was calculated for agreement on the diagnosis CRPS of hand surgeon and pain specialist.

The variable distribution was tested visually with boxplot and Kolmogorov-Smirnov-test for normal distribution. In contradicting cases, we assumed normal distribution. We tested differences of continuous variables with the paired t-test and of categorical variables using the chi-square test or Fisher's exact depending on the expected values.

\section{Results}


The patients had an average age of 49 years (SD 9.5, $\mathrm{Cl} 47.62-51.27$ ). Differences between male and female patients are shown in Table 1. As there was only a difference in age, further analysis was performed for pooled data. Four cases were not considered CRPS by clinical assessment and Budapest criteria resulting in 120 cases with CPRS and a prevalence of $97.8 \%$ in our sample. Four excluded cases were one patient with neuropathic pain of the forearm and reduced functionality after correction osteotomy of malunited distal radius fracture, one patient with neuropathic pain of the forearm after plating of distal radius fracture and one patient with neuropathic pain after complex injury of the hand. The last patient did not meet three criteria of the symptom list on admission but was diagnosed CRPS later.

Table 1

\begin{tabular}{|llll|}
\hline & male & female & p \\
\hline $\mathrm{n}$ & 53 & 71 & \\
\hline Age (mean) & 47 SD 9 & 51 SD 9 & 0.006 \\
\hline Right hand affected & $25(46 \%)$ & $29(54 \%)$ & 0.482 \\
\hline Right hand dominant & $47(89 \%)$ & $66(93 \%)$ & 0.407 \\
\hline Dominant hand affected & $25(47 \%)$ & $34(48 \%)$ & 0.937 \\
\hline $\begin{array}{l}\text { Budapest criteria met } \\
\text { CRPS diagnosis by hand surgeon }\end{array}$ & 49 & 59 & 0.124 \\
\hline $\begin{array}{l}\text { CRPS diagnosis by pain specialist } \\
\text { (n male = 45, female = 63) }\end{array}$ & 29 & 62 & 0.573 \\
\hline $\begin{array}{l}\text { Differences between male and female patients. We used the unpaired t-test for comparison of age. } \\
\text { Hand dominance was tested with Fisher's exact. All other categorical variables were tested with chi- } \\
\text { square including numbers for left hand, non-dominance, and negative diagnosis, which can be } \\
\text { deduced from total and given values. Total values for CRPS diagnosis by pain specialist differ and } \\
\text { are given in the table. }\end{array}$ & 45 & 0.441 \\
\hline
\end{tabular}


Table 2

\begin{tabular}{|c|c|c|}
\hline Budapest criterium that was not met & $\begin{array}{l}\text { Clinically } \\
\text { CRPS }\end{array}$ & $\begin{array}{l}\text { Clinically no } \\
\text { CRPS }\end{array}$ \\
\hline 1. Continuing pain, which is disproportionate to any inciting event & 1 & - \\
\hline 2. Sensory and vasomotor & 10 & 1 \\
\hline 2. Sensory and sudomotor/edema & - & 1 \\
\hline 2. Vasomotor and sudomotor/edema & 1 & - \\
\hline 2. Sensory, vasomotor, sudomotor/edema & 0 & 1 \\
\hline $\begin{array}{l}\text { 4. There is no other diagnosis that better explains the signs and } \\
\text { symptoms }\end{array}$ & 0 & 1 \\
\hline
\end{tabular}

Budapest criteria were met in 108 cases (87\%). Their mean CSS was 10.41 points (SD 1.7, Cl 10.0910.72 ) and significantly higher than the score of 8.44 (SD 1.8, Cl 7.50-9.37) of patients without CRPS according to the Budapest criteria $(p<0.001$, unpaired $t$-test).

Eleven of 120 cases (9\%) had fewer than three symptoms in category 2 and are considered CRPS-NOS. They had a CSS of 8.50 (SD 1.7, Cl 7.43-9.57). The hand surgeons diagnosed CRPS in 10 of 11 CRPSNOS patients, the pain specialists in 4 of 11 .

Values for diagnostic accuracy are shown in Table 3. The agreement between hand surgeon and pain specialist for the diagnosis CRPS was fair ( $k a p p a=0.291, n=104$, Table 4). Values for female and male patients are provided in supplementary tables 1 and 2 . 
Table 3

\begin{tabular}{|lllll|}
\hline & \multicolumn{2}{c}{ Hand surgeons $\mathbf{n}=124$} & \multicolumn{2}{c|}{ Pain specialists $\mathbf{n = 1 0 8}$} \\
\hline & Value & $95 \% \mathrm{Cl}$ & Value & $95 \% \mathrm{Cl}$ \\
\hline Sensitivity & 91.67 & $84.77-96.12$ & 74.47 & $64.43-82.91$ \\
\hline Specificity & 31.25 & $11.02-58.66$ & 71.43 & $41.90-91.61$ \\
\hline Positive Likelihood Ratio & 1.33 & $0.95-1.86$ & 2.61 & $1.13-6.02$ \\
\hline Negative Likelihood Ratio & 0.27 & $0.10-0.70$ & 0.36 & $0.22-0.58$ \\
\hline Positive Predictive Value & 98.34 & $97.70-98.81$ & 99.14 & $98.05-99.63$ \\
\hline Negative Predictive Value & 7.78 & $3.13-18.04$ & 5.92 & $3.75-9.22$ \\
\hline Accuracy & 90.34 & $83.72-94.91$ & 74.40 & $65.10-82.31$ \\
\hline Predictive values and accuracy & were calculated for a prevalence of $97.8 \%$ in our sample. \\
\hline
\end{tabular}

Table 4

\begin{tabular}{|lllc|}
\hline CRPS & $\mathrm{n}=108$ & \multicolumn{2}{l|}{ Pain specialist } \\
\cline { 3 - 4 } Hand surgeon & & Yes & No \\
\cline { 2 - 4 } & Yes & 72 & 25 \\
\cline { 2 - 4 } & No & 2 & 9 \\
\hline
\end{tabular}

Sixty-nine of 72 cases (96\%) with agreement on CRPS and 19 of 27 cases (70\%) with contradicting opinion of hand surgeon and pain specialist met the Budapest criteria for CRPS. Six of $9(67 \%)$ cases with clinical agreement on non-CRPS met the Budapest criteria.

\section{Discussion}

Our results show the difficulty of diagnosing CRPS. Hand surgeons and pain specialist showed only a fair agreement on the diagnosis. Considering the Budapest criteria as gold standard, hand surgeons showed a higher sensitivity and accuracy than the pain specialists who showed a higher specificity. When both specialties agreed on CRPS, the Budapest criteria were met in $96 \%$ thus showing its value. In all other cases, the criteria were met in around $70 \%$. This would support the use of the Budapest criteria for quick detection of patients at risk for referral to a specialist.

As most patients were admitted with suspicion or diagnosis of CRPS, we had a high prevalence in our sample. This does not reflect the ambulatory care where the number of false positive cases would be higher. But early referral to a specialist permits early and proper treatment. 
As each patient would be seen by only one hand surgeon on admission, differences between them cannot be determined. The low agreement with pain specialist suggests the specialties did not influence each other in a major way.

The CSS of patients with CRPS according to the Budapest criteria is in range with the values of the original publication that introduced CSS (8). While the values are naturally lower in patients who do not meet the Budapest criteria, the likelihood for CRPS might be represented in the score.

We found $9 \%$ CRPS-NOS which is less than the previously reported $15 \%$ but may be related to the preselection bias (11). Late diagnosis of CRPS-NOS might delay treatment. Similar to the higher sensitivity, hand surgeons also diagnosed CRPS in more cases of CRPS-NOS than pain specialists.

It is likely that there are false positive cases in our sample as we used the criteria for the clinical setting which have a reported specificity of $69 \%$. In addition, the hand surgeons show an even lower specificity that cannot be explained.

\section{Conclusion}

The Budapest criteria can support the diagnosis CRPS in clinically ambiguous cases as they were most often met in cases with agreement of both clinicians. Care must be taken not to miss patients with CRPSNOS.

\section{List Of Abbreviations}

CRPS complex regional pain syndrome

CSS CRPS severity score

CRPS-NOS CRPS-not otherwise specified

SD standard deviation of the mean

Cl 95\% confidence interval

\section{Declarations}

Ethics approval and consent to participate

The local institutional ethics committee of the University of Greifswald approved the study (BB BB 104/19) and stated that there are no ethical or legal concerns regarding this study. The decision was based on the Helsinki declaration. We obtained written consent from the patients included in the study.

Consent for publication 
Not applicable

Availability of data and materials

The datasets generated and analysed during the current study are available in the Mendeley Data repository, http://dx.doi.org/10.17632/yc9mnx36wj.2

Competing interests

The authors declare that they have no conflict of interest.

Funding

No funding was received

Author Contribution

PJ Project development, Data collection and analysis, Manuscript writing

AA Data collection, Manuscript editing

SPE Data collection, Manuscript editing

$\mathrm{AE} \quad$ Data management and interpretation, Manuscript editing

MM Data collection, Manuscript editing

JD Project development, Data analysis

SK Project development, Data management, Data analysis and interpretation, Manuscript writing

All authors have read and approved the manuscript.

\section{References}

1. Veldman PH, Reynen HM, Arntz IE, Goris RJ. Signs and symptoms of reflex sympathetic dystrophy: prospective study of 829 patients. Lancet. 1993;342(8878):1012-6.

2. de Mos M, de Bruijn AG, Huygen FJ, Dieleman JP, Stricker BH, Sturkenboom MC. The incidence of complex regional pain syndrome: a population-based study. Pain. 2007;129(1-2):12-20.

3. Allen G, Galer BS, Schwartz L. Epidemiology of complex regional pain syndrome: a retrospective chart review of 134 patients. Pain. 1999;80(3):539-44.

4. de Rooij AM, Perez RS, Huygen FJ, van Eijs F, van Kleef M, Bauer MC, et al. Spontaneous onset of complex regional pain syndrome. Eur J Pain. 2010;14(5):510-3. 
5. Shim H, Rose J, Halle S, Shekane P. Complex regional pain syndrome: a narrative review for the practising clinician. Br J Anaesth. 2019;123(2):e424-e33.

6. Harden RN, Bruehl S, Perez RS, Birklein F, Marinus J, Maihofner C, et al. Validation of proposed diagnostic criteria (the "Budapest Criteria") for Complex Regional Pain Syndrome. Pain. 2010;150(2):268-74.

7. Stanton-Hicks M, Janig W, Hassenbusch S, Haddox JD, Boas R, Wilson P. Reflex sympathetic dystrophy: changing concepts and taxonomy. Pain. 1995;63(1):127-33.

8. Harden RN, Bruehl S, Perez RS, Birklein F, Marinus J, Maihofner C, et al. Development of a severity score for CRPS. Pain. 2010;151(3):870-6.

9. Harden RN, Maihofner C, Abousaad E, Vatine JJ, Kirsling A, Perez R, et al. A prospective, multisite, international validation of the Complex Regional Pain Syndrome Severity Score. Pain. 2017;158(8):1430-6.

10. Harden RN, Bruehl S, Galer BS, Saltz S, Bertram M, Backonja M, et al. Complex regional pain syndrome: are the IASP diagnostic criteria valid and sufficiently comprehensive? Pain. 1999;83(2):211-9.

11. Harden RN, Bruehl S, Stanton-Hicks M, Wilson PR. Proposed new diagnostic criteria for complex regional pain syndrome. Pain Med. 2007;8(4):326-31.

\section{Supplementary Files}

This is a list of supplementary files associated with this preprint. Click to download.

- SupplementaryMaterial.docx 